\title{
Reflexiones desde la salud pública sobre un libro desconcertante
}

\author{
Reflections on a disconcerting book from the public health \\ view point
}

\section{Luis Carlos Silva Ayçaguer}

Doctor en Ciencias. Académico Titular. Investigador Titular. Centro Nacional de Información de Ciencias Médicas. La Habana, Cuba.

\section{RESUMEN}

La presente reseña profundiza en los contenidos del libro "Salud Ecológica" desde la perspectiva de la Salud Pública. Si bien se trata de un texto que recopila información de valor histórico y cultural, que contiene atinadas denuncias a diversas expresiones de mercantilismo con implicaciones negativas para la salud de los ciudadanos, desde el punto de vista científico, se trata de un libro fallido. El texto amalgama afirmaciones basadas en el esoterismo, la defensa de corrientes creacionistas y las infundamentadas a diversos procedimientos diagnósticos 0 terapéuticos, todo en el contexto de un manejo marcadamente deficiente de la bibliografía. El libro refleja no sólo la posición de sus autores, sino que es representativo de una corriente de pensamiento que colisiona contra elementos ontológicos, epistemológicos y salubristas básicos. La valoración crítica desde la lógica convencional y la racionalidad que aquí se realiza abre un espacio para el debate que es medular para la genuina defensa de la salud colectiva.

Palabras clave: Pseudociencia, creacionismo, Edward Bach, salud pública, comunicación científica.

\section{ABSTRACT}


The present paper delved into the contents of the book entitled "Salud Ecológica" from the public health viewpoint. Although this is a text that gathers information of historical and cultural values, and contains pertinent denunciations of several mercantilist expressions having negative impact on the population's health, it is a failed book from the scientific viewpoint. The book combines esoterism-based statements, the defense of creationist currents and unsubstantiated praises of several diagnostic or therapeutic procedures, together with markedly deficient management of literature. It not only reflects the position of the authors but also represents a school of thought at odds with basic ontological, epistemological and public health elements. The critical appraisal presented here from conventional logics and rationality opens up the possibilities for debate, which is fundamental for the genuine defense of the collective health.

Key words: Pseudoscience, creationism, Edward Barch, public health, scientific communication.

\section{NTRODUCCI ÓN}

"Salud Ecológica"1 es el título de un libro de aliento humanista que, en palabras de sus autores, "pretende dar una visión de la medicina, de forma integradora y holística" a partir de "un fondo socio-cultural que demuestra la posibilidad y la necesidad de un cambio de paradigma en la ciencia". Esta declaración de propósitos anuncia análisis de evidente interés para la salud pública.

En efecto, el texto rescata información de valor histórico y cultural. Los autores denuncian en varios puntos diversos males de la sociedad capitalista contemporánea que comprometen la salud pública. Sus advertencias acerca de las perversiones asociadas al mercantilismo, sus atinadas prevenciones sobre los efectos de la codicia de las transnacionales del medicamento y su defensa de la ecología, son ejemplos de una tesitura altruista y noble que no puede sino ser bienvenida.

Sin embargo, desde el punto de vista científico, se trata de un libro malogrado; tanto, que resultaría una tarea ingente detenerse en cada aserción o sugerencia del libro que merezca un comentario crítico. En primer lugar, porque ello supondría escribir un texto quizás más extenso que el propio libro, debido a que una afirmación desatinada puede ser muy breve, mientras que la reflexión razonada para refutarla puede llevar considerable espacio. $Y$ en segundo lugar, porque hay zonas y nociones tan crípticas, que difícilmente pueden valorarse desde la lógica convencional y la racionalidad.

Por consiguiente, opto por una variante más humilde: comentar-sin atender necesariamente al orden en que aparecen- algunos segmentos que a mi juicio son suficientemente representativos de los rasgos señalados como para relevarme del deber de ser exhaustivo.

Las ideas que se exponen en el presente artículo, animadas por la lectura del libro, configuran una reseña crítica sobre dicho texto, pero también y sobre todo 
constituyen un vehículo para compartir nociones de naturaleza ontológica, epistemológica y salubrista, así como reflexiones generales sobre la comunicación científica.

La presente edición de "Salud Ecológica" exhibe un rasgo curioso y muy inusual: a continuación del prólogo se han incluido varias opiniones de profesionales que aconsejaron su publicación. Algunas son francamente entusiastas; otras son más cautas, sin dejar de ser elogiosas. Miradas en conjunto, integradas como un todo junto con el texto, configuran un compacto posicionamiento que no incluye dudas ni reparos. Consecuentemente, también comentaré brevemente algunas de dichas convalidaciones externas.

\section{DETERMI NACI ONES PENDULARES DE LOS TRASTORNOS}

En la página 33 el lector puede hallar el siguiente párrafo, que reproduzco textualmente:

Siempre ha sido muy interesante un procedimiento o disciplina que se conoce en la actualidad con el nombre de radiestesia.... La técnica de radiestesia se utiliza desde hace miles de años por muchos pueblos, y usan el péndulo o varillas flexibles de madera o metal para la búsqueda de agua, minerales $u$ objetos perdidos....Estos planteamientos parecen ser muy válidos, principalmente cuando se utiliza la teleradiestesia, o sea, radiestesia a distancia. También se puede emplear para el diagnóstico médico; con el péndulo sobre una fotografía o sobre el diagrama de una figura humana, se pueden conocer las afecciones orgánicas, emocionales, bioquímicas o energéticas que presenta esa persona, con muy poco margen de error, si se posee el entrenamiento y los conocimientos convenientes.

Ignoro en qué podrán basarse los autores para afirmar que la radiestesia se emplea desde hace milenios para, por ejemplo, buscar objetos extraviados. Sin embargo, esto es irrelevante. Desde hace miles de años se emplean conjuros mágicos para "resolver" problemas, sin que ello adicione mérito alguno a tales procedimientos.

Los autores nos informan sin más trámite que estos planteamientos "parecen ser muy válidos". No sólo no lo justifican, sino que adicionan que tales métodos son especialmente útiles cuando se aplican a distancia (mediante "teleradiestesia"). Lo que entiendo es que si se me pierde un objeto, alguien podría, usando una varilla, descubrir su paradero. Esto es considerablemente turbador; pero la sugerencia de que, si el zahorí está más distante, su capacidad para ubicar dicho objeto sería aún mayor, es de por sí portentosa e intrínsecamente contradictoria.

A continuación los autores se internan en materia diagnóstica: se asegura que un sujeto "debidamente entrenado" y con los "conocimientos adecuados", con sólo mover un péndulo sobre una fotografía del paciente o, incluso, sobre un croquis dibujado del mismo, puede identificar sus afecciones orgánicas o bioquímicas. ¿Cómo se consigue tal entrenamiento? ¿A qué conocimientos se hace referencia y cómo se obtienen? Con esta afirmación se convalidan procedimientos que contradicen frontalmente el sentido común y el conocimiento médico, arduamente conseguido durante siglos de investigación y actuación de los científicos. ¿Cuáles son las evidencias empíricas corroborables y las bases teóricas que permiten sostener tamaña expectativa? De un delirante plumazo se estremecen los cimientos de la radiología, de los exámenes de laboratorio, de la anatomía patológica... y en general, de todos los procedimientos diagnósticos de la ciencia médica. 
Uno de los valedores del libro, el físico Hugo Pérez Rojas, destacado profesor e investigador, comunica que "no he encontrado en la obra ningún concepto físico o afirmación contradictoria con los hechos de la física establecida". Invito a dicho especialista a que nos informe, por ejemplo, en qué zona de la literatura especializada se hallan los elementos que permiten afirmar que moviendo una varilla en determinadas coordenadas, se pueda descubrir el sitio en que se ubica un objeto extraviado en una zona distante; y sobre todo, qué área teórica de la Física establecida respalda que, haciendo pendular un objeto sobre la fotografía de un paciente se pueden conocer sus trastornos psíquicos, bioquímicos y orgánicos.

\section{REI VI NDI CACIÓN DE LA ASTROLOGÍ A}

En la página 30 se escribe lo siguiente:

Como si la tierra hubiera tenido el sumo cuidado de que, en cada producto de la creación, exista una memoria biológica para modificar el estado de saludenfermedad de los seres vivos, más que eso, la propiedad de interrelacionarse con estos, para proporcionar mecanismos que armonicen sus energías. Este proceso resulta en direcciones múltiples: entre la tierra y los seres vivos, entre los seres vivos y la tierra, y entre todos los seres vivos entre sí en los diferentes ecosistemas; esta memoria está determinada por la calidad del terreno, el clima, la temperatura, la energía contenida en las manos que siembran, las variaciones electromagnéticas del espacio, la organización de los planetas, la cantidad de radiaciones que nos llegan, etcétera. La sábila y el ajo de Piscis no son iguales que el ajo y la sábila de Acuario.

En principio no resulta evidente a qué le llaman los autores "la tierra". Pero, a juzgar por lo que puede leerse, se ha llamado "la tierra" a una entidad inteligente, capaz de tener cuidado en sus actos de "creación".

A raíz de la ofensiva llevada a cabo en EE.UU. en defensa del "creacionismo", la Academia Nacional de Ciencias de Estados Unidos, por ejemplo, ha fijado su posición señalando que "esta corriente de pensamiento, el diseño inteligente y otros reclamos de una intervención sobrenatural en el origen de la vida o de las especies no son ciencia." 2 En EE.UU., tanto la Asociación Nacional de Profesores de Ciencia, como la Sociedad Americana para el Avance de la Ciencia, han calificado estas ideas, directamente, como pseudociencia (véanse detalles en http://en.wikipedia.org/wiki/Intelligent_design). Análoga posición ha sido adoptada por el National Center for Science Education (NCSE), la organización que lidera el anticreacionismo y defiende que en las escuelas públicas se enseñe la biología evolucionista en lugar de los enfoques religiosos impulsados por el conservadurismo republicano (véase

http://en.wikipedia.org/wiki/National_Center_for_Science_Education).

Los autores están en su derecho de respaldar el creacionismo, aunque esté altamente desacreditado en los círculos científicamente cultos. A lo que no tienen derecho, técnicamente hablando, es a hacer afirmaciones sin fundamentarlas, tales como que todos los "productos de la creación" ( por ejemplo, una estrella lejana o una piedra volcánica ubicada a muchos kilómetros en el subsuelo marino) tienen algo a lo que llaman "memoria biológica", capaz de modificar el estado de salud de los seres vivos. Se trata de una afirmación que, en la medida que se formula mediante categorías no definidas y en un vacío de referencias y antecedentes consultables, no puede ser comprendida, si es que algo significa. 
Pero he aquí que la idea se cierra abruptamente con la siguiente oración: "La sábila y el ajo de Piscis no son iguales que el ajo y la sábila de Acuario". Hay algo a lo que se le llama "la sábila de Piscis" y otra cosa a la que se le denomina "sábila de Acuario", y estás dos cosas son diferentes. Me pregunto qué quiere decir que son diferentes. Me pregunto si hay también "sábila de Géminis" o "ajo de Sagitario" o "boniatos de Capricornio". Y sobre todo me pregunto qué tendrá que ver ese galimatías zodiacal con lo que se venía escribiendo.

La madeja de divagaciones astrales, sin embargo, se complica. A continuación de lo anterior se enuncia algo bastante enigmático:

Como existen hombres que por su relación con los astros son Sagitario o Serpiente, Escorpión o Conejo, por su nivel de concentración de los oligoelementos que lo conforman, serán hombres-ajos, hombres-calabazas u hombres-eucaliptus.

De inmediato se abunda sobre los hombres-calabaza, ahora vinculándolos a algo que se denomina "frecuencia vibratoria de un estado". Y de ahí se pasa a dar información acerca de factores de riesgo, una herramienta operativa medular para la Epidiemiología y la Salud Pública: los hombres-calabaza están más protegidos a ciertas dolencias que aquellos que no son hombres-calabaza. Veamos:

Nos referimos a un estado cuya frecuencia vibratoria, en el caso del hombrecalabaza, tiene una memoria especial para los elementos como: ácido kaínico, luteína, ß-caroteno, alcoholes terpénicos, manganeso y zinc. Además, posee mayor resistencia a padecer adenoma benigno de la próstata y parasitismo por Taenia, Áscaris y Oxiuros.

Ante tal laberinto de palabras, uno no puede menos que recordar a Richard Smith, quien fuera durante 23 años editor jefe de British Medical Journal cuando decía:

Soy suspicaz ante las ideas que son supuestamente tan profundas y complejas que no pueden ser expresadas en un lenguaje que todo el mundo puede entender. Es posible que existan tales ideas, pero yo no conozco ninguna. ${ }^{3}$

También viene a la mente el célebre aforismo de Nietzsche: "Las explicaciones místicas pasan por profundas: la verdad es que no son siquiera superficiales."

Cuesta trabajo admitir que la salud de la población pueda verse en lo más mínimo beneficiada por aportes de este tenor, o por nociones como las que son objeto de análisis en la siguiente sección. Tampoco es fácil aceptar que, como se afirma en el prólogo, que con ellos se pueda llenar un vacío en los conocimientos y la cultura general de un profesional de la medicina o del público en general.

\section{BRACI ONES, ESOTERISMOS Y MUÑECOS DE PALO}

En la página 57 leemos:

Si volvemos al principio de correspondencia expresado por Hermes Trimegisto (como es arriba es abajo), se supone que el resto del universo puede tener patrones de organización que se correspondan. Cuando se piensa en la Tierra, como un organismo que autorregula sus condiciones de humedad, temperatura, gases, corrientes marinas y otras condiciones, puede que exista un patrón de 
organización, donde se pudieran encontrar semejanzas con los sistemas de circulación de la energía de los seres que la habitan, el cual sería equivalente a meridianos de acupuntura y chakras o vórtices de energía. Del mismo modo ocurriría con el sol, los planetas del sistema solar y su interacción recíproca, así como con el universo, como un todo.

Apoyándose en el principio que reza "como es arriba es abajo", elaborado por Hermes Trimegisto, se sacan conclusiones tales como que el resto del universo ( $i e l$ resto respecto de qué?) puede tener patrones organizativos que se correspondan (¿qué se correspondan con qué?). Resulta francamente difícil enjuiciar una afirmación tan incompleta y, por ende, carente de sentido claro. Aparentemente, se está diciendo que tan curioso principio legitimaría la idea de que ciertos mecanismos que supuestamente gobiernan la relación de los cuerpos celestes se estarían reproduciendo en los seres que habitan la tierra.* En ese punto se intercala sin ton ni son una mención a meridianos, chakras y "vórtices de energía". Soy incapaz de seguir este viaje verbal hacia la nada. Lo que sí he podido hacer es averiguar quién era Hermes Trimegisto.

Según Wikipedia (http://es.wikipedia.org/wiki/Hermes Trimegisto) Hermes Trimegisto fue durante la Edad Media el creador de la llamada Hermética. Sus textos gozaban de gran crédito y eran populares entre los alquimistas. La "tradición hermética", se refiere a la alquimia, la magia, la astrología y otros temas relacionados. La llamada Hermética, o "literatura Hermética", es una categoría de papiros que contienen hechizos y procedimientos de inducción mágica". Estamos pues ante un típico cultor de las imposturas medievales (la astrología, la nigromancia, la alquimia y la cábala), conceptuado sin embargo por los autores del libro (página 27) como "gran sabio."

Cuesta trabajo admitir que algún principio entresacado de la aberrante palabrería de la hechicería practicada por semejante celebridad - mucho menos uno tan pueril y difuso como el que proclama "como es arriba, es abajo"- pueda tener el menor valor para comprender las leyes de la naturaleza y la sociedad. El libro de los doctores Ávila y Fonte, sin embargo, va más lejos por ese camino. Así, en la página 57 se incluye el siguiente segmento:

Cuando se analiza "la imagen del muñeco de palo", se puede pensar en un sistema de flujo energético en todo el universo, organizado, interconectado con todo, que interactúa en diversas dimensiones.

La ley esencial del universo es la vibración, flujo y reflujo; esta idea está presente en muchas culturas:

En el principio era el verbo y el verbo era Dios

Donde la acción de la palabra, tendrá un efecto modificador de la materia.

Todo fue hecho del Verbo y sin Verbo nada fue hecho.

(San Juan 1: 1-3).

Por su singular naturaleza generalizadora, ya que se trata nada menos que de la ley básica según la cual se rige todo el universo, y muy especialmente, por ser de todo punto ininteligible, creo que al declarar que la "ley esencial del universo es la vibración", se hace la aseveración que más estupor produce en todo el libro. Aparentemente, tal conclusión ha sido alcanzada por los autores mediante un silogismo que parte del muñeco de palo y se basa en el exótico axioma creacionista tomado de La Biblia según el cual las palabras modifican a la materia.

Con otro de los comentaristas preliminares, el Dr. Julio Fernández Bulté, quien fuera un destacado jurista de nuestro país, sí tengo algunas coincidencias. Por 
ejemplo, comparto su afirmación de que en el libro "no hay falsos esoterismos". En efecto, ninguno es falso: todos los que figuran en el libro, que son muchos, son verdaderos esoterismos. Y también estoy de acuerdo con su afirmación de que el material "constituye un instrumento político y militante de la ciencia, vista desde las posiciones comprometidas del Tercer Mundo", sobre todo por sus muy atinadas denuncias al mercantilismo capitalista, a la cacería obscena del dinero a costa de la ecología y a las transnacionales del medicamento. Pero, debido a su marcado y recurrente carácter opuesto al materialismo dialéctico y su contribución a sedimentar la incultura científica, lamentablemente, también desempeña un papel político negativo.

\section{UN RECORRI DO RELI GI OSO Y LOS EVANGELI OS}

En la página 87 del libro se inicia un largo recorrido por el mundo de la religión. A modo de introducción, los autores dan cuenta sobre diferentes credos que, a no dudarlo, tienen millones de fieles en el planeta. En ese contexto informan sobre las ideas de Darwin y diferentes hipótesis científicas acerca del nacimiento de la vida y su evolución. Aunque no es demasiado claro el vínculo entre la salud humana y tal preámbulo, y más allá de la opinión que pudiera merecer a un especialista la forma en que este último se encara, no advierto en principio nada objetable en ello. Pero lo cierto es que el texto desemboca inesperadamente en una especie de sermón evangelizador. Los autores pasan a la primera persona del plural para hacernos advertencias admonitorias tales como las siguientes:

No podemos contemplar impasibles cómo manchan su karma y conformarnos con la idea de que tendrán más culpas que limpiar en futuras reencarnaciones, o que serán condenados en el juicio final porque estamos perdiendo almas de Dios. (Página 94).

No creemos que nadie pueda culpar solo a los ateos de esta crisis de espiritualidad, los creyentes también intervienen en ese fenómeno que se está desarrollando. (Página 96).

Hay que pedir arrepentimiento sincero, que se muestre en actitudes y obras concretas; probablemente así se pierdan algunos falsos creyentes, pero se ganará muchos otros, con verdadera fe y el mejoramiento de los demás. (Página 97).

Así, extensos pasajes del cuarto capítulo son destinados a la exaltación de valores religiosos que nada tienen que ver con el afán de elevar el estado de salud de la población, a la postre la razón de ser de la literatura médica. El capítulo, por más señas, concluye con el siguiente texto:

Cristo transmitió las enseñanzas a sus discípulos, a los que dio la misión de divulgar el evangelio entre todos los hombres. Las actuales iglesias son las depositarias de esa misión, asignada por Jesucristo para defender sus doctrinas de amar a Dios de todo corazón y amar al prójimo como a sí mismo: ASí SEA. (Nota: mayúsculas en el original).

La prédica religiosa es un derecho de cualquier ciudadano que merece todo respeto, del mismo modo que lo merecen los sentimientos de fe que aparentemente embargan a los autores; pero pretender que el misticismo y las invocaciones divinas pueden ayudarnos a comprender el mundo es algo difícilmente compatible con un pensamiento racional. El humanismo a veces subyacente en las doctrinas de esta índole constituye a mi juicio un valor de la cultura universal, con virtudes que a muchos ayuda en su tránsito por la vida. Tal convicción no contradice mi personal 
adhesión al materialismo y al ateísmo. Pero un libro supuestamente científico, que se oriente a promover la salud de los ciudadanos, debería desentenderse de aquello que es exclusivamente privativo del dogma religioso, además de no ser el espacio adecuado para actuar como portavoz de los evangelios ni para explicar la misión de las iglesias.

\section{EL VI H, EL SI DA Y LA I NFORMACIÓN PARCI AL}

Algunos pasajes del libro (las primeras diez páginas del Capitulo IV, por ejemplo) recogen con lucidez y firmeza una serie de reflexiones valiosas para la Salud Pública sobre el papel de la medicina y los hábitos de vida occidentales relacionados con la salud. Sin embargo, esas reflexiones desembocan más adelante en una información parcializada cuando discute el problema actual del VIH y el SIDA. El libro informa al respecto que:

El doctor Peter Duesberg (profesor de Biología Molecular en la Universidad de California, Berkely, pionero en el estudio de los retrovirus, y candidato al Premio Nobel por el descubrimiento de los oncogenes en virus) afirma que no cree que el retrovirus VIH cause SIDA, y argumenta que infecta muy pocas células, es demasiado inactivo y muy difícil de que sea responsable de los pacientes con SIDA.

Sólo una precisión de momento, que retomaré más adelante: Duesberg no dice que "sea muy difícil" que el VIH cause el SIDA sino que afirma de manera tajante que no influye en la enfermedad; en su libro "Inventando el virus del sida" ${ }^{4}$ sostiene que la hipótesis de VIH/SIDA es un "error infernal" $y$, de hecho, insiste en que el VIH es "inofensivo". Más concretamente, este laureado científico contestatario sostiene que dicho retrovirus consigue ocasionalmente hallar un camino dentro del cuerpo de aquellos cuyos sistemas están inmunodeprimidos pero que, en sí mismo, es absolutamente inocuo. ${ }^{5}$

En ese punto los autores de "Salud Ecológica" agregan (página 86) que:

Cada vez se incrementan más los científicos que piensan acerca del SIDA como una enfermedad inventada, que es útil para los negocios, así como el beneficio adicional para ayudar a controlar el crecimiento demográfico en el mundo, por las muertes que causa y las limitaciones en las relaciones sexuales, pues se insiste que esta vía (sexual) es la más importante para la transmisión de la enfermedad.

Lamentablemente, no se nos ofrece dato alguno que nos convenza de que el número de científicos que cree que el SIDA es una "enfermedad inventada" crece sin cesar. Más adelante, los autores dan su aval al punto de vista alternativo que han expuesto y lo expresan del modo siguiente:

Existen sobradas razones para pensar que los argumentos anteriores, sustentados en una alternativa diferente a la del VIH-SIDA, tienen mucha validez. El mundo conoce de lo que es capaz el mercantilismo, la avidez de ganancias y de dominación del capitalismo neoliberal. Sin embargo, aunque aquí se aprueba casi todo lo planteado en este enfoque alternativo, aún falta mucho por saber acerca del SIDA, y no se acepta negar su existencia de forma absoluta; aquí no se adopta una posición intermedia que excluya el compromiso de nuestras ideas, pero se ofrece al lector otros argumentos para que pueda razonar con claridad sin inducirlo a posiciones extremas. 
En principio, no objeto que se informe acerca de una polémica existente ni el hecho de que los autores consideren que hay "sobradas razones" para creer que el VIH no causa el SIDA. Me parece legítimo que se expongan los argumentos de Peter Duesberg y sus seguidores, aunque artículos publicados, incluso en la prestigiosa revista Science, los califiquen como pseudocientíficos. ${ }^{6} \mathrm{Y}$ resulta especialmente pertinente que se denuncie la inescrupulosidad que suele envolver a determinadas empresas que comercian con la enfermedad.

Lo que resulta inaceptable es que se omitan totalmente los puntos de vista y evidencias opuestas a la posición que defienden, las cuales, obviamente, son cruciales para conseguir que el lector "pueda razonar con claridad sin inducirlo a posiciones extremas", propósito que, según declaran, anima a los autores. En un artículo reciente, ${ }^{7}$ entre otras reglas generales que gozan del apoyo universal de la comunidad científica en torno al intercambio de ideas y el debate científico serio, enuncié lo siguiente: "La información externa a que se apele durante la discusión debe ser correcta, completa, precisa y accesible." La violación de esta pauta obstaculiza que se pueda razonar con claridad; más bien contribuye a generar un estado de confusión que habría de evitarse con el máximo celo en una materia de primera importancia para la salud pública.

No soy un experto en el tema y no puedo pronunciarme con rigor en torno a la polémica, pero sí puedo testimoniar que también existen "sobradas razones" para creer que Duesberg está equivocado y que el retrovirus (VIH) es el responsable de la inmunodepresión que ha dado en llamarse SIDA, aunque en el libro sean omitidas. Para fundamentarlo, por no extenderme en el frondoso respaldo de las ciencias básicas, clínicas y epidemiológicas de que se dispone (véase la exhaustiva y actualizada exposición de las evidencias que brindan los Institutos de la Salud de Estados Unidos en http://www.niaid. nih.gov/factsheets/evidhiv.htm ), considero oportuno mencionar sólo tres de tales razones:

1. En el año 2000 se produjo la llamada Declaración de Durban ${ }^{8}$ titulada "A Declaration by Scientists and Physicians Affirming HIV is the Cause of AIDS", que fue suscrita nada menos que por unos 5000 expertos, la mayoría de ellos notables científicos, así como por prestigiosas instituciones tales como la US National Academy of Sciences, la Royal Society of London, los institutos Max Planck, la European Molecular Biology Organization, el US Institute of Medicine y el Instituto Pasteur de París. La lista íntegra de los firmantes puede consultarse en Internet (http://www. aidstruth.org/the-durban-declaration-signatories.pdf). El documento señala que reafirmar la relación causa-efecto entre VIH y SIDA de manera tan amplia y contundente es medular para tratar de evitar las trágicas consecuencias que tendría seguir negando las "claras, exhaustivas e inequívocas pruebas existentes."

2. Las dudas que despierta Duesberg entre encumbrados investigadores no son desdeñables. Luc Montagnier, descubridor del VIH afirma que "Duesberg, deliberadamente o no, opera con solo una parte de los datos, lo cual lo lleva a defender una posición totalmente equivocada". Montagnier no es un aficionado ni un asalariado de la industria farmacéutica que merezca ser ignorado, sino nada menos que el director de la Fundación Mundial para la Investigación y la Prevención del Sida, quien, por cierto, acaba de recibir el Premio Nobel de Fisiología o Medicina 2008, precisamente como recompensa a su descubrimiento del $\mathrm{VIH}$ como agente causal del SIDA en la década de los 80.

3. El virólogo norteamericano Michael Fumento ha emplazado reiteradamente a Duesberg. Textualmente, escribía en Los Angeles Times ${ }^{9}$ que, puesto que Duesberg 
estaba dispuesto a consentir que otros mueran al apoyar su convicción de que el VIH es inocuo "...el año pasado lo desafié públicamente a que se dejara inyectar ante testigos con una forma purificada del virus. No lo ha hecho, dando las más variadas excusas. Ahora extiendo la invitación a todos sus seguidores."

\section{UN DESFI LE DE TERAPIAS SI N REFERENCI AS}

La lectura del libro recuerda a una especie de cajón de sastre donde se alude encomiásticamente a diversos recursos diagnósticos o terapéuticos caracterizados por el misticismo, el manejo de categorías misteriosas que no se definen, energías que nadie ha medido, y nociones indescifrables, todo -y esto es lo más inquietantesin citas que lo respalden ni, mucho menos, alusión a las numerosas críticas de que han sido objeto. Así, en el Capítulo VI vemos desfilar, entre varios otros, recursos tales como:

- El poder de la "energía piramidal", cuya existencia ha sido refutada teóricamente por los físicos, ${ }^{10,11}$ negada por varios estudios publicados en Cuba ${ }^{12-14}$ y emplazada públicamente sin que hasta ahora nadie haya querido hacer la experiencia que podría contribuir a dirimirlo. ${ }^{15}$

- "La homeopatía", un proceder extendido en algunos medios y practicado desde hace dos siglos en no pocos lugares del planeta, elogiado con vehemencia por sus cultores, pero duramente criticado en revistas y foros científicos del máximo nivel.**

- La "aurículopuntura", concebida a partir de la idea de que todos y cada uno de los órganos y tejidos del cuerpo humano están representados en la oreja por conducto de un hombrecito imaginario anidado como un feto en dicho órgano auditivo, cuya naturaleza fantasiosa ha sido resaltada desde hace muchos años. ${ }^{16}$

- La "imposición de manos", recurso según el cual un terapeuta intercambia energía con el cuerpo de un paciente a través de sus manos sin llegar a tocarlo. Esta modalidad ha sido ridiculizada con insistencia. Quizás el trabajo más famoso, por haber sido publicado en una revista de primer nivel y porque su autora principal fue una niña de Colorado que ideó un simple pero exitoso experimento*** para demostrar que se trataba de una patraña. ${ }^{17}$

- La "curación cuántica" impulsada por Deepak Chopra, un médico y astrólogo norteamericano de origen hindú quien se ha enriquecido con sus libros esotéricos (algunos de los títulos son: "Conocer A Dios", "El Sendero Del Mago", "Iluminación", "Un Ángel se acerca", "Curación Cuántica") y ha conseguido notoriedad por su adhesión a la teoría del "diseño inteligente" del universo según la cual la teoría darwiniana de la evolución de las especies no tiene validez, ${ }^{18}$ así como por haber sido merecedor del Premio Ig Nobel**** de Física en el año 1998.

- La "terapia floral" de Edward Bach, personaje a quien el libro rinde tributo en tanto "observador de gran agudeza" gracias a la cual consiguió encontrar los remedios florales. El libro menciona que tal recurso carece de fundamentos demostrados, pero nada se dice acerca de las varias demostraciones ${ }^{19-23}$ de que dicha terapia no es superior a un simple placebo. 
Podría extenderme enjuiciando cada uno de estos recursos; pero no es esa la finalidad de esta valoración. Lo que me parece crucial destacar es la falta de rigor presente en la forma de manejar estas informaciones. Para ilustrarlo, y por ser poco conocida, me detendré en la figura de Edward Bach, el inventor de la terapia floral.

\section{EDWARD BACH Y LA CIENCI A: ENEMI GOS DECLARADOS}

El creador de la terapia floral no era un hombre de ciencias. Fue simplemente un ser trasnochado que renegaba explícitamente del pensamiento científico por considerarlo un estorbo pernicioso. Me remito a su obra. En la introducción de su tratado "La curación por las flores", ${ }^{24}$ escribe textualmente:

Este sistema de tratamiento es el más perfecto que se le ha ofrecido a la humanidad desde tiempos inmemoriales. Tiene el poder de curar las enfermedades; y por ser sencillo, puede utilizarse en casa. Su sencillez precisamente, unida a sus efectos de curación de todo, hacen que sea maravilloso. No se requiere ciencia alguna, ni conocimientos previos, aparte de los sencillos métodos que aquí se describen; y los que más beneficios conseguirán de este regalo enviado por Dios serán aquellos que lo conserven tan puro como es: libre de ciencia y de teorías, pues todo en la naturaleza es muy simple. Este sistema de curación, que se nos ha revelado por conducto divino, demuestra que nuestros temores, nuestras preocupaciones, nuestras ansiedades y demás son los que abren la puerta a la invasión de la enfermedad. (Nota: los subrayados son del autor de la presente reseña).

Es decir, según el propio Edward Bach testimonia, Dios se comunicó con él y le dio a conocer la terapia. La naturaleza divina de tal revelación para la que fue elegido, le exonera de tener en cuenta la ciencia. Esto lo dice reiteradamente en su libro "Los remedios florales: Escritos y Conferencias" 25 donde se ofrece una definición de la enfermedad ciertamente sorprendente:

La enfermedad es la consecuencia de la resistencia de la personalidad frente al liderazgo del alma que se manifiesta corporalmente.... La enfermedad del cuerpo, en sí misma, no es otra cosa más que el resultado de la desarmonía entre el alma y el espíritu.

Como profesional con 30 años de trabajo en materia de salud pública, disciplina para la cual la definición de este concepto es medular a los efectos de cumplir sus funciones (prevenir las enfermedades, prolongar la vida, fomentar la salud y la eficiencia física y mental), ${ }^{26,27}$ sólo puedo explicarme tamaño dislate cuando observo que los escritos de Bach son, por encima de ninguna otra cosa, un manifiesto religioso escrito por un iluminado. Una y otra vez en los citados escritos y conferencias se hallan consideraciones que desdeñan el valor de la observación crítica, el cotejo, la experimentación, recursos considerados pecaminosos, ya que vendrían a perturbar la verdadera fuente del saber: la voz de Dios y nuestra capacidad potencial de escucharla. He aquí un ejemplo:

Nuestra alma -suave y delicada voz, la propia voz de Dios- nos habla a través de nuestra intuición, nuestros instintos, nuestros deseos, ideales, nuestras preferencias y desafectos habituales. Estas órdenes deben ser acatadas sin rechistar, porque únicamente el alma sabe qué experiencias son necesarias para el desarrollo de nuestra personalidad individual. Debemos tener la certeza de que 
únicamente existe un pecado: el pecado de no obedecer las órdenes de nuestra propia divinidad. (Nota: los subrayados son del autor de la presente reseña).

De una manera que roza la obsesividad, propia de un profeta ensimismado, la obra de Bach está plagada de afirmaciones relacionadas con la enfermedad, donde explícitamente se señala que no importa qué es verdad y qué no desde el punto de vista racional, ya que es Dios quien nos provee de convicciones al respecto y no debemos incurrir en el pecado de usar nuestro intelecto. Juzgue el lector un segmento típico de tales textos:

Queremos volver a dejar claro que nuestra enfermedad corporal no juega ningún papel. Es el estado de nuestro espíritu, y sólo eso, lo que importa. Cada enfermedad, sea todo lo grave que se quiera, puede ser curada siempre que se recupere la felicidad del paciente. Salud significa obedecer las órdenes de nuestra alma, ser confiados como un niño pequeño, mantener el intelecto a raya con sus argumentos lógicos. No es necesario analizar la verdad, ni justificarla o hablar demasiado sobre ella. (Nota: los subrayados son del autor de la presente reseña).

Para concluir el tema, cabe consignar que el libro afirma que "esta terapia fue reconocida por la OMS en 1976". Desafortunadamente, volvemos a chocar contra la falta de referencias. ¿Qué quiere decir "reconocida"? Este es un adjetivo ambiguo, ya que puede significar que la Organización Mundial de la Salud simplemente consigna que este procedimiento se emplea en algunos sitios y, por otra parte, que garantiza o destaca su validez más allá del efecto placebo. Son dos cosas totalmente diferentes, pues lo primero es un hecho objetivo, mientras que lo segundo supondría un aval técnico. Personalmente, no he podido hallar documento alguno que registre esto último. Hasta donde conozco, se trata meramente del reconocimiento de que en ciertas comunidades existen sectores que creen en el poder curativo de las esencias florales y aplican dichos procedimientos. Se ha llamado la atención ${ }^{28}$ acerca de que para entender el asunto basta reparar en algunas de las otras terapias incluídas en el listado de la OMS, entre las que se halla el espiritismo y la medicina mágica africana.

\section{EL MANEJ O DE LAS FUENTES DOCUMENTALES}

El manejo de la literatura configura la endeblez estructural más seria del libro. En primer lugar, los libros y artículos que figuran en la bibliografía no están referenciados (acotados) en el texto. Siendo así, no queda claro qué papel desempeñan dichas obras en tanto apoyo bibliográfico de lo que se expone, una deficiencia que puede generar serios conflictos al lector. En realidad, no sólo no están acotados sino que la mayoría de ellos ni siquiera son mencionados ni directa ni indirectamente en el texto. Por poner un ejemplo, en esa lista se incluye el insólito trabajo titulado "De la Homeopatía a la Biología Digital" donde Jacques Benveniste afirmaba que se podían conseguir curas homeopáticas a través del correo electrónico, obra por la cual también se hizo merecedor del premio Ig Nobel***** de química en 1998. Pero no se puede saber en virtud de qué aparece en dicha lista, ya que ni el autor ni la obra son mencionados en el cuerpo del libro. También ocurre al revés: ideas y autores exaltados en el texto no tienen una obra de respaldo incluida en la lista (por ejemplo, no figura nada de lo escrito por Peter Duesberg). 
Por eso sorprende especialmente que en uno de los comentarios preliminares se subraye que lo conseguido por los autores esté "fundamentado en una amplia revisión bibliográfica." Puede ser que las 87 obras ( 65 libros, 19 artículos, 1 conferencia y 2 obras de origen desconocido) que integran la lista de referencias pueda considerarse "amplia" (esto es esencialmente subjetivo), pero es enteramente objetivo que el lector no puede considerar que dicha lista sea un fundamento de lo que se ha escrito, ni que lo que leemos está basado en dicha revisión, debido a la ausencia de todo nexo entre ambas cosas.

Por otra parte, la manera de citar las obras es anárquica: como puede corroborarse fácilmente, para algunos libros figura la editorial pero no la ciudad, otros tienen la ciudad pero no la editorial y otros, ninguna de las dos cosas; algunos tienen fecha, otros no, entre otros. Con los 19 artículos citados, lamentablemente, pasa algo similar: algunos tienen volumen y páginas; en otros sólo figura el volumen o ambos datos están ausentes, y para algunos artículos no aparece siquiera el nombre de la revista que los publicó.

\section{CONSI DERACI ONES FI NALES}

Hace unos años señalé que las sociedades han desarrollado experiencias y sistematizado formas especiales de conocimiento acerca de la salud y la enfermedad. Ellas han ido configurando un conjunto de actuaciones salidas de la práctica empírica informal y espontánea de la gente común, hasta llegar a nociones que concentran y sistematizan la experiencia secular de la colectividad. Y adicioné que este saber informal, de indudable valor cultural, ha de ser conservado o recuperado. ${ }^{29}$ En ese sentido, el libro prometía ser un interesante esfuerzo complementario al arsenal de recursos conceptuales y operativos de que disponemos. Pero, independientemente de las buenas intenciones de los autores, del valor informativo que puedan tener algunos pasajes y de la enérgica defensa de la naturaleza que el texto recoge, habida cuenta de sus numerosas deficiencias, el balance general es claramente desfavorable.

La pertinencia de su publicación puede ser motivo de polémica. Pero lo cierto es que el libro refleja no sólo la posición de sus dos autores, sino que, a juzgar por el conjunto de elogiosos avales iniciales, encarna una corriente de pensamiento que prevalece en muchos colegas. La aparición del texto tiene la virtud de dejar registrada la existencia de dicha corriente. Pero la información científica tiene la encomienda de acrisolar el conocimiento mediante la transparencia del lenguaje, la objetividad y la crítica libremente ejercida desde la racionalidad. Por eso la publicación de "Salud Ecológica" tiene también el mérito de propiciar el debate que, cuando se desarrolla con ecuanimidad y honradez, siempre oxigena y termina siendo fecundo para la genuina defensa de la salud colectiva.

\section{REFERENCI AS BI BLI OGRÁFI CAS}

1. Ávila J, Fonte P. Salud Ecológica. La Habana: Editorial Ciencias Médicas; 2004.

2. National Academy of Sciences. Science and Creationism. Washington, D.C.: National Academy Press; 1999. 
3. Smith R. The trouble with medical journals. London: Royal Society of Medicine Press; 2006.

4. Duesberg P. Inventing The AIDS Virus. New York: Regnery Publisher; 1997.

5. Duesberg PH. AIDS acquired by drug consumption and other noncontagious risk factors. Pharmacy and Therapy. 1992;55:201-77.

6. Makgoba MW. HIV/AIDS: the peril of pseudoscience. Science. 2000; 288: 1171.

7. Silva LC. Claves para el desarrollo del debate científico. Revista Cubana de Física. 2008; 25: 9- 12 .

8. The Durban Declaration. A Declaration by Scientists and Physicians Affirming HIV is the Cause of AIDS. Nature. 2000;406: 15-6.

9. Fumento M. A Complicated Disease Won't Have Simple Answers. Los Angeles Times. 1992, July 28.

10. González A. Falsas energías, pseudociencia y medios de comunicación masiva. Revista Cubana de Física. 2002; 19:68-73.

11. de Melo O. Energías vitales y piramidales. El espejismo de las seudociencias. Semanario Orbe. 2003; Año V, No. 26.

12. Rebullido PD, Silva LC, Benet M. Valoración experimental del efecto de la energía piramidal sobre el agua. Medisur. 2006; 4:44-7.

13. Hernández PL, Perera A, Ulloa A. Una valoración experimental de la energía piramidal. Implicaciones para la práctica médica. Rev Cubana Med Gen Integr [serie en Internet]. 2007[citado 26 Mar 2008];23(4). Disponible en: http://scielo.sld.cu/scielo.php?script=sci_arttext\&pid=S0864$\underline{21252007000400004 \& \operatorname{lng}=e s \& n r m=i s o}$

14. Álvarez J Ausencia de "efecto piramidal" sobre cardiomiocitos aislados de rata. Rev Cubana Investig Bioméd [serie en Internet]. 2007[citado 26 Mar 2008]; 26(3). Disponible en: http://scielo.sld.cu/scielo.php?script=sci_arttext\&pid=S0864$03002007000300007 \& \operatorname{lng}=\mathrm{es} \& \mathrm{nrm}=\mathrm{iso}$

15. Silva LC. Sobre la existencia del Ilamado "efecto piramidal". Una propuesta experimental. Revista Cubana de Física. 2008;25:28-33.

16. Skrabanek P, McCormick J. Sofismas y desatinos en medicina. Barcelona: Doyma; 1992.

17. Rosa L, Rosa E, Sarner L, Barrett S. A Close Look at Therapeutic Touch. J AMA. 1998;279: 1005-10.

18. Shermer M. Skyhooks and Cranes: Deepak Chopra, George W. Bush, and Intelligent Design [actualizado 2005, citado 26 Mar 2009]. Disponible en: http://www.huffingtonpost.com/michael-shermer/skyhooks-and-cranesdeep_b_6179.html 
19. Ernst E. Flower remedies: a systematic review of the clinical evidence. Wien Klin Wochenschr. 2002; 114:963-6.

20. Walach $\mathrm{H}$, Rilling $\mathrm{C}$, Engelke U. Efficacy of Bach-flower remedies in test anxiety: a double-blind, placebo-controlled, randomized trial with partial crossover. J Anxiety Dis. 2001;15(4):359-66.

21. Armstrong N, Ernst E. A randomised, double-blind, placebo-controlled trial of a Bach Flower Remedy. Perfusion. 1999; 11:400-46.

22. Oliff HS. Bach flower remedy ineffective in clinical trial on university students taking exams. Perfusion. 2000; 12:440-6.

23. Pintov S, Hochman M, Livne A, Heyman E, Eli Lahat E. Bach flower remedies used for attention deficit hyperactivity disorder in children -A prospective double blind controlled study. Eur J Paediatric Neurol.2005; 9:395-8.

24. Bach E. La curación por las flores. Madrid: Editorial Edaf; 1991.

25. Bach E. Los remedios florales. Escritos y Conferencias. Dr. Edward Bach. (1932/1993). Madrid: Editorial Edaf; 1993.

26. Breslow L, editor. Encyclopedia of Public Health. New York: Gale Group, Inc.; 2002.

27. De la Torre, López C, Márquez M, Gutiérrez J A, Rojas F. Salud para todos sí es posible. La Habana: Sociedad Cubana de Salud Pública; 2005.

28. Gimenez G ¿Aromas de Salud? Exactamente [actualizado 1996, citado 26 Mar 2009]. Disponible en:

http://www.fcen.uba.ar/publicac/revexact/exacta7/exaindex.htm

29. Silva LC. Ciencia y pseudociencia: una distinción crucial. Rev Cubana Investig. Bioméd. 1997; 16: 78-82.

Recibido: 24 de febrero de 2009.

Aprobado: 10 de marzo de 2009.

Luis Carlos Silva Ayçaguer. Centro Nacional de Información de Ciencias Médicas. La Habana, Cuba.

E-mail: Ics@inflmed.sld.cu 
* Por cierto, decir que los seres vivos de nuestro planeta están abajo mientras que los cuerpos celestes están "arriba" es de por si una afirmación disparatada.

** Los artículos y comentarios críticos que se hallan en las revistas científicas se cuentan por cientos, de modo que no resulta necesario citas que lo pongan de manifiesto.

*** Por cierto, sería interesante que alguno de tales terapeutas se sometiera públicamente a esta misma experiencia en nuestro medio.

$* * * *$ Los premios Ig Nobel son una parodia de los Nobel, organizada por la revista de humor científico Annals of I mprobable Research y la Universidad de Harvard para ridiculizar estudios especialmente absurdos o ignominiosos. (véanse detalles en http://es.wikipedia.org/wiki/Premio Ig_Nobel\#cite_ref-22).

$* * * * *$ Oficialmente, Benveniste fue galardonado "por su importante descubrimiento en Homeopatía, que indica que el agua no sólo tiene memoria, sino que esta información se puede transmitir a través de la Red Telefónica y de Internet." 